\title{
Potentiometric Study of Complexation between Taurine and Metal Ions
}

\author{
Yu. S. Petrova and L. K. Neudachina \\ Ural Federal University named after the first President of Russia B.N.Yeltsin, Yekaterinburg, Russia \\ Received April 17, 2012
}

\begin{abstract}
The protolytic and complexation properties of taurine are studied by a potentiometric method. The dissociation constants of 2-aminoethanesulfonic acid functional groups and the stability constants of taurine complexes with copper(II), cobalt(II), nickel(II), zinc(II), manganese(II), cadmium(II), silver(I), magnesium(II), calcium(II), strontium(II), and barium(II) ions are calculated.
\end{abstract}

DOI: $10.1134 /$ S0036023613050173

\section{THEORETICAL ANALYSIS}

Taurine (2-aminoethanesulfonic acid) is a biologically active compound. It occurs in all vital organs of a human body. Taurine is frequently classified with sulfurcontaining amino acids; although unlike these amino acids, it contains no carboxylic group. Only the fact that taurine is present in aqueous solutions as a zwitterion and can be found in short-chain peptides makes it somewhat related to amino acids. A number of researchers classify taurine with vitamin-like substances due to its diverse biological activities [1].

Taurine is a potential ligand for metal ions. The presence of a donating oxygen atom in the sulfo group of taurine implies that 2-aminoethanesulfonic acid has an affinity to so-called A-cations (cations with the electronic shell of an inert gas) [2]. It is theoretically possible that 2-aminoethanesulfonic acid can also form complexes with so-called B-cations (cations with 10 or $(10+2)$ electrons in the outer shell) and transition metal ions due to the presence of an amino group in its composition [2]. However, the complexation properties of taurine have been insufficiently described. Singh and Singh [3] studied the stability of taurine complexes with heavy-metal ions by paper electrophoresis. This method is not strictly quantitative; hence, Singh and Singh's results [3] cannot be considered to be adequately reliable. The scarce published data regarding the stability of taurine complexes with silver(I) [4], copper(II) [5], calcium(II) [6], and nickel(II) [7] ions require additional verification. Of the studies devoted to the complexation properties of taurine, studies into stability of taurine complexes with silver(I) and cadmium(II) ions [8] and studies into stability of copper(II) complexes with mixed ligands comprising taurine [9] are worth mentioning.

Here, we study potentiometrically the stability of complexes formed by taurine and copper(II), cobalt(II), nickel(II), zinc(II), manganese(II), cad-
mium(II), silver(I), magnesium(II), calcium(II), strontium(II), and barium(II) ions.

\section{CALCULATIONS}

The $\mathrm{p} K_{\mathrm{a}}$ values of the functional groups of taurine at each titration point were calculated using the formula below that took into account the corrections for concentration of hydroxide ions (at $\mathrm{pH}>10)$ (1) and hydrogen ions $($ at $\mathrm{pH}<4)(2)[10]$ :

$$
\begin{gathered}
\mathrm{p} K_{\mathrm{a}}=\mathrm{pH}+\log \frac{[\mathrm{HA}]+\left[\mathrm{OH}^{-}\right]}{\left[\mathrm{A}^{-}\right]-\left[\mathrm{OH}^{-}\right]}, \\
\mathrm{p} K_{\mathrm{a}}=\mathrm{pH}+\log \frac{[\mathrm{HA}]-\left[\mathrm{H}^{+}\right]}{\left[\mathrm{A}^{-}\right]+\left[\mathrm{H}^{+}\right]},
\end{gathered}
$$

where $\mathrm{pH}$ is the current acidity of the medium, $\left[\mathrm{H}^{+}\right]$ and $\left[\mathrm{OH}^{-}\right]$are the equilibrium concentrations of hydrogen ions and hydroxide ions, and [HA] and $\left[\mathrm{A}^{-}\right]$ are the equilibrium concentrations of the protonated and deprotonated taurine forms, respectively. The $\mathrm{p} K_{\mathrm{a}}$ values calculated at each titration point were averaged.

Two functions, [L] and $n$, were calculated in order to determine the stability constants of taurine complexes with metal ions with $1: 1$ and $1: 2$ ratios $\left(\beta_{1}\right.$ and $\beta_{2}$, respectively). Here, $[\mathrm{L}]$ is the concentration of unbound species that are capable of chelating, which was calculated using formula [10]:

$$
\begin{aligned}
& \log [\mathrm{L}]=\log \left(\left[\mathrm{L}_{0}\right]-[\mathrm{KOH}]-\left[\mathrm{H}^{+}\right]\right. \\
& \left.+\left[\mathrm{OH}^{-}\right]\right)-\log \left(\frac{\left[\mathrm{H}^{+}\right]}{K_{\mathrm{a}}}+\frac{2\left[\mathrm{H}^{+}\right]^{2}}{K_{\mathrm{a}} K_{\mathrm{a}}^{\prime}}\right),
\end{aligned}
$$

where $\left[\mathrm{L}_{0}\right]$ is the concentration of the initially added ligand, $[\mathrm{KOH}]$ is the alkali concentration in the titrated solution; $K_{\mathrm{a}}$ and $K_{\mathrm{a}}^{\prime}$ are the constants of dissociation of the ligand ( $K_{\mathrm{a}}$ refers to the higher $\mathrm{p} K_{\mathrm{a}}$ value and takes into account unprotonated species). If a 
Table 1. Acid dissociation constants of taurine $(\mu=$ $0.1 \mathrm{~mol} / \mathrm{L}, \mathrm{KCl}, T=20 \pm 1^{\circ} \mathrm{C}$ )

\begin{tabular}{c|c|c}
\hline $\begin{array}{c}\text { Dissociation } \\
\text { constant }\end{array}$ & This study & Published data \\
\hline $\mathrm{p} K_{1}$ & 1.68 & $1.5[5]$ \\
$\mathrm{p} K_{2}$ & $8.93 \pm 0.02$ & $1.54 \pm 0.04[7]$ \\
& & $9.95[4]$ \\
& & 8.08 [5] \\
& & $9.01 \pm 0.03[7]$ \\
& & $8.90 \pm 0.01[9]$ \\
\hline
\end{tabular}

Note: $\mathrm{p} K_{1}$ is the dissociation constant of the sulfo group of taurine according to the equation $\mathrm{HO}_{3} \mathrm{SCH}_{2} \mathrm{CH}_{2} \mathrm{NH}_{2} \leftrightarrow \mathrm{H}^{+}+$ ${ }^{-} \mathrm{O}_{3} \mathrm{SCH}_{2} \mathrm{CH}_{2} \mathrm{NH}_{2} ; \mathrm{p} K_{2}$ is the dissociation constant of the amino group of taurine according to the equation $\mathrm{HO}_{3} \mathrm{SCH}_{2} \mathrm{CH}_{2} \mathrm{NH}_{3}^{+} \leftrightarrow \mathrm{HO}_{3} \mathrm{SCH}_{2} \mathrm{CH}_{2} \mathrm{NH}_{2}+\mathrm{H}^{+}$.

solution is titrated with an acid, the equation is transformed in such a way that $[\mathrm{KOH}]$ is replaced by $[\mathrm{HCl}]$.

$n$ is the average number of ligand molecules bound to a single metal ion:

$$
n=\frac{\left[\mathrm{L}_{0}\right]-\alpha\left[\mathrm{L}^{-}\right]}{\left[\mathrm{M}_{0}\right]},
$$

where $\left[\mathrm{M}_{0}\right]$ is the total concentration of a metal (either free or bound).

The $\alpha$ value is determined according to the following expression:

$$
\alpha=\frac{\left[\mathrm{H}^{+}\right]}{K_{\mathrm{a}}}+\frac{\left[\mathrm{H}^{+}\right]^{2}}{K_{\mathrm{a}} K_{\mathrm{a}}^{\prime}}+1
$$

The expressions for the stepwise dissociation constants were given in [10]:

$$
\begin{aligned}
K_{1} & =\frac{n}{(1-n)\left[\mathrm{L}^{-}\right]}, \\
K_{2} & =\frac{n-1}{(2-n)\left[\mathrm{L}^{-}\right]} .
\end{aligned}
$$

However, they were obtained based on an assumption that the $2: 1$ complex is formed during the titration only after the formation of the $1: 1$ complex is completed. In order to allow for the possible overlapping between the existence regions of these complexes, the accurate values of the stability constants of taurine complexes with metal ions ( $1: 1$ and $1: 2$ compositions; $\beta_{1}$ and $\beta_{2}$, respectively) were calculated by linearization of the following function [10-12]:

$$
\frac{n}{(1-n)\left[\mathrm{L}^{-}\right]}=\beta_{1}+\beta_{2}\left(\frac{2-n}{1-n}\right)\left[\mathrm{L}^{-}\right] .
$$

As advised in [5], the $n$ values belonging to the ranges of $0.1-0.7$ and $1.3-1.7$ were used in linearizing function (8).

\section{EXPERIMENTAL}

The potentiometric titration of aqueous solutions was carried out in an inert atmosphere of nitrogen at ionic strength $(\mu)$ of $0.1 \mathrm{~mol} / \mathrm{L} \mathrm{KCl}\left(\mathrm{KNO}_{3}\right)$ and $20 \pm 1^{\circ} \mathrm{C}$ using an I-160MI ion meter equipped with a glass electrode (ES-10603) and a saturated silver/silver chloride (ESr-10103) electrode. The ion meter was calibrated using standard buffer solutions. Solutions containing $2 \mathrm{mmol} / \mathrm{L}$ taurine in the presence and absence of $1 \mathrm{mmol} / \mathrm{L}$ metal salt were studied. In investigating the complexation between taurine and easily hydrolyzable ions of metals (zinc(II) or copper(II)), titration was carried out in solutions with ligand concentration of $30 \mathrm{mmol} / \mathrm{L}$.

The metal was monitored complexonometrically. A $0.084 \mathrm{mmol} / \mathrm{L}$ of carbonate-free potassium hydroxide solution was used as a titrant. At least three titration curves were recorded for each series of solutions.

\section{RESULTS AND DISCUSSION}

Since there is a certain inconsistency between the published dissociation constants of amino group $\left(\mathrm{p} K_{2}\right)$ and sulfo group $\left(\mathrm{p} K_{1}\right)$ in taurine, their values were determined in this study (Table 1 ).

Thus, the resulting values of the acid dissociation constants of functional groups of taurine are comparable to the same values described in literature.

The amino group within taurine is characterized by a lower acid dissociation constant as compared to that of $\beta$-alanine (aminopropanoic acid, $\mathrm{p} K_{2}=10.36$ [5]). This can be apparently attributed to the fact that the sulfo group has a stronger negative inductive effect as compared to that of the carboxylic group, which results in a decrease in electron density on the nitrogen atom of the taurine amino group and, hence, a decrease in its basicity.

It has been mentioned in the literature [13] that the accurate values of dissociation constants cannot be obtained within the ranges of $\mathrm{p} K<3$ and $\mathrm{p} K>11$. This is due to the fact that the compounds containing, for instance, strongly acidic groups, are titrated at very low $\mathrm{pH}$ values. In this situation, the criterion of the constancy of ionic strength is violated; hence, all data obtained are characterized by a large scatter [10]. Thus, the value of the dissociation constant of the strongly acidic sulfo group ( $\mathrm{p} K_{1}=1.68$, Table 1$)$ cannot be considered to be accurate.

The reagents containing a donating oxygen atom are known to be analytically valuable for A-cations [2]. However, data concerning the stability of the cal- 
Table 2. Stability constants of taurine complexes with Group IIA metal ions $\left(\mu=0.1 \mathrm{~mol} / \mathrm{L}, \mathrm{KCl}, T=20 \pm 1^{\circ} \mathrm{C}\right.$

\begin{tabular}{c|c|c|c}
\hline $\begin{array}{c}\text { Metal } \\
\text { ion }\end{array}$ & $\begin{array}{c}\text { Ionic radii according } \\
\text { to Belov-Bokii, nm } \\
{[14]}\end{array}$ & $\log \beta_{1} *$ & $\log \beta_{2}$ \\
\hline $\mathrm{Mg}$ (II) & 0.074 & $2.80 \pm 0.26$ & $6.28 \pm 0.02$ \\
$\mathrm{Ca}$ (II) & 0.104 & $2.78 \pm 0.13$ & $6.25 \pm 0.02$ \\
$\mathrm{Sr}(\mathrm{II})$ & 0.120 & $2.57 \pm 0.17$ & $6.18 \pm 0.01$ \\
$\mathrm{Ba}(\mathrm{II})$ & 0.138 & $2.46 \pm 0.18$ & $6.17 \pm 0.02$ \\
\hline
\end{tabular}

* Calculated using formula (6) for $n=0.1-0.7$.

Note: Here and below, $\log \beta_{1}$ are $\log \beta_{2}$ are logarithms of the stability constants of taurine complexes with metal ions $\left(\mathrm{M}^{2+}\right)$ for the equilibria $\mathrm{M}^{2+}+{ }^{-} \mathrm{O}_{3} \mathrm{SCH}_{2} \mathrm{CH}_{2} \mathrm{NH}_{2} \leftrightarrow$ $\mathrm{M}\left(\mathrm{O}_{3} \mathrm{SCH}_{2} \mathrm{CH}_{2} \mathrm{NH}_{2}\right)^{+}$and $\mathrm{M}^{2+}+2^{-} \mathrm{O}_{3} \mathrm{SCH}_{2} \mathrm{CH}_{2} \mathrm{NH}_{2} \leftrightarrow$ $\mathrm{M}\left(\mathrm{O}_{3} \mathrm{SCH}_{2} \mathrm{CH}_{2} \mathrm{NH}_{2}\right)_{2}$, respectively.

cium(II) complex with taurine [6] require additional verification, while the complexation properties of taurine with respect to magnesium(II), strontium(II), and barium(II) ions have not been described. In this study, the data of potentiometric titration were used to calculate the stability constants of taurine complexes with Group IIA metal ions (Table 2).
It should be mentioned that the $\log \beta_{1}$ values determined using Eq. (8) are negative, which is presumably due to the fact that it is difficult to calculate relatively $\operatorname{low} \log \beta_{1}$ values using this method [5]. Hence, the stability constants of the taurine : metal complexes (with composition $1: 1$ ) were determined by averaging the $\log \beta_{1}$ values calculated using formula (6) at $n=0.1-0.7$. It has been noted [13] that the constants cannot be accurately measured in any of concentration ranges at $\log \beta=2$. Therefore, the confidence interval values obtained for $\log \beta_{1}$ (Table 2 ) are relatively high.

The complexes where metal : ligand $=1: 2$ are the most stable taurine complexes with metal ions (Table 2), which is rather natural, taking into account the charges of metal cations and the sulfo group. It should be mentioned that the stability constant of a complex decreases as the ionic radius of the corresponding element is reduced (Table 2). This fact indicates that the ionic bond considerably contributes to the formation of the metal-ligand bond, which is a characteristic feature of A-cations [2].

The amino group in taurine is a potential ligand with respect to transition-metal ions and the $\mathrm{B}$-cations $[2$, $11,12]$. Hence, the stability constants of taurine complexes with copper(II), zinc(II), cobalt(II), nickel(II), manganese(II), silver(I), and cadmium(II) ions were determined in this study by potentiometric titration (Table 3 ). The titration curves of taurine recorded in the

Table 3. Stability constants of complexes of transition metal ions with taurine $\left(\mu=0.1 \mathrm{~mol} / \mathrm{L}, \mathrm{KCl}\left(\mathrm{KNO}_{3}\right), T=20 \pm 1^{\circ} \mathrm{C}\right.$ and ammonia [14]

\begin{tabular}{|c|c|c|c|c|c|c|}
\hline \multirow{2}{*}{ Metal ion } & \multicolumn{2}{|c|}{ This study } & \multicolumn{2}{|c|}{ Published data } & \multirow{2}{*}{$\log _{[14]} \beta_{1}\left(\mathrm{NH}_{3}\right)$} & \multirow{2}{*}{$\underset{[14]}{\log \beta_{2}\left(\mathrm{NH}_{3}\right)}$} \\
\hline & $\log \beta_{1}$ & $\log \beta_{2}$ & $\log \beta_{1}$ & $\log \beta_{2}$ & & \\
\hline $\mathrm{Cu}(\mathrm{II})$ & $3.56 \pm 0.07$ & $6.52 \pm 0.20$ & $4.5\left(20^{\circ} \mathrm{C}\right) *[5]$ & $8[5]^{* *}$ & 3.99 & 7.33 \\
\hline $\mathrm{Zn}(\mathrm{II})$ & - & $5.00 \pm 0.03$ & - & - & 2.18 & 4.43 \\
\hline $\mathrm{Ni}(\mathrm{II})$ & $2.77 \pm 0.05$ & $5.52 \pm 0.14$ & - & - & 2.67 & 4.79 \\
\hline $\mathrm{Co}(\mathrm{II})$ & $2.09 \pm 0.34$ & $5.37 \pm 0.10$ & - & - & 1.99 & 3.50 \\
\hline $\operatorname{Mn}(\mathrm{II})$ & - & $5.28 \pm 0.07$ & - & - & 0.8 & 1.3 \\
\hline $\operatorname{Ag}(\mathrm{I})$ & $3.05 \pm 0.05$ & $6.41 \pm 0.01$ & $\begin{array}{c}3.53 \pm 0.07\left(25^{\circ} \mathrm{C}, 1 \mathrm{~mol} / \mathrm{L}\right. \\
\left.\mathrm{NaClO}_{4}\right)[8] ; 3.19\left(25^{\circ} \mathrm{C}\right. \\
\left.0.014 \mathrm{~mol} / \mathrm{L} \mathrm{KNO}_{3}\right)[4]\end{array}$ & $\begin{array}{c}6.47 \pm 0.05\left(25^{\circ} \mathrm{C}, 1 \mathrm{~mol} / \mathrm{L}\right. \\
\left.\mathrm{NaClO}_{4}\right)[8] ; 6.38\left(25^{\circ} \mathrm{C},\right. \\
\left.0.014 \mathrm{~mol} / \mathrm{L} \mathrm{KNO}_{3}\right)[4]\end{array}$ & 3.32 & 7.23 \\
\hline $\mathrm{Cd}(\mathrm{II})$ & $2.78 \pm 0.03$ & $5.28 \pm 0.11$ & $\begin{array}{c}2.05 \pm 0.10\left(25^{\circ} \mathrm{C}, 1 \mathrm{~mol} / \mathrm{L}\right. \\
\left.\mathrm{NaClO}_{4}\right)[8]\end{array}$ & $\begin{array}{c}3.74 \pm 0.08\left(25^{\circ} \mathrm{C}, 1 \mathrm{~mol} / \mathrm{L}\right. \\
\left.\mathrm{NaClO}_{4}\right)[8]\end{array}$ & 2.51 & 4.74 \\
\hline
\end{tabular}

Notes: * Calculated for $n<0.3$;

** Calculated using formula (9);

Note: $\log \beta_{1}\left(\mathrm{NH}_{3}\right)$ and $\log \beta_{2}\left(\mathrm{NH}_{3}\right)$ are logarithms of the stability constants of complexes of ammonia with metal ions $\left(\mathrm{M}^{2+}\right)$ for the equilibria $\mathrm{M}^{2+}+\mathrm{NH}_{3} \leftrightarrow \mathrm{M}\left(\mathrm{NH}_{3}\right)^{2+}$ and $\mathrm{M}^{2+}+2 \mathrm{NH}_{3} \leftrightarrow \mathrm{M}\left(\mathrm{NH}_{3}\right)_{2}^{2+}$, respectively. 


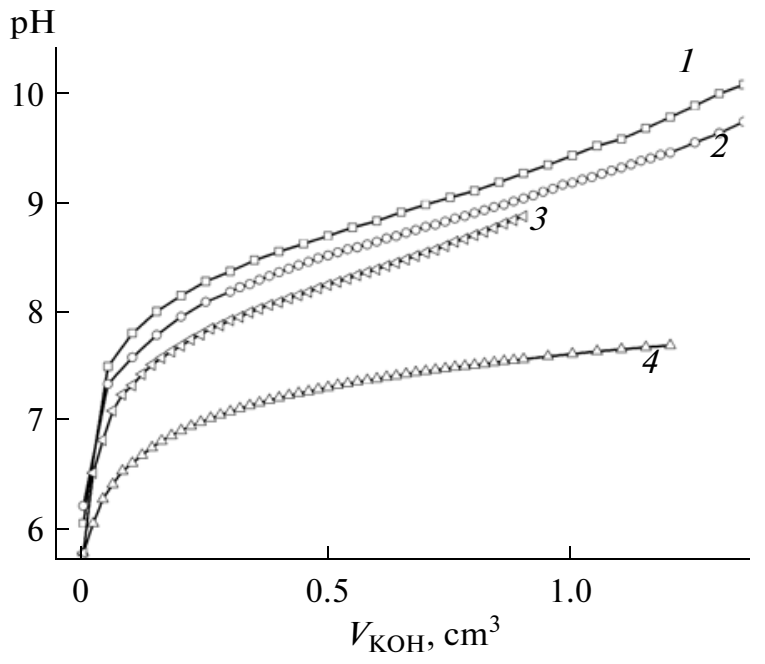

$\mathrm{pH}$ curves for titration of solutions of $(1)$ taurine $\left(c_{\text {taurine }}=\right.$ $2 \mathrm{mmol} / \mathrm{L})$, (2) taurine in the presence of magnesium(II) $\left(c_{\mathrm{Mg}^{2+}}=1 \mathrm{mmol} / \mathrm{L}\right),(3)$ silver(I) $\left(c_{\mathrm{Ag}^{+}}=1 \mathrm{mmol} / \mathrm{L}\right)$, and (4) $\operatorname{zinc}(\mathrm{II})\left(c_{\mathrm{Zn}^{2+}}=1 \mathrm{mmol} / \mathrm{L}, c_{\text {taurine }}=30 \mathrm{mmol} / \mathrm{L}\right)$ with $\mathrm{KOH}$ solution $\left(c_{\mathrm{KOH}}=0.084 \mathrm{mmol} / \mathrm{L}\right)$.

absence and presence of magnesium(II), silver(I), and zinc(II) ions are shown in the figure as an example.

Since copper(II) and zinc(II) ions precipitate in the form of hydroxides at relatively low $\mathrm{pH}$ values, these metals were titrated in a large excess of the ligand (at a taurine : metal ion ratio $=30: 1$ ), as advised in [13]. The results are listed in Table 3.

The stability constants of taurine complexes with copper(II) [5] were determined via titration of the complexes under study with hydrochloric acid. For this reason, values $n>0.3$ could not be achieved during the titration. This circumstance disabled the calculation of the $\log \beta_{2}$ value for taurine complexes with copper(II) ions by linearizing expression (8). Meanwhile, $\log \beta_{2}$ was calculated [5] using the formula

$$
\log \beta_{2}=2 \log \beta_{1}-1 \text {. }
$$

It should be mentioned that this equation holds for $\alpha$-amino acids. However, it can turn out to be invalid in calculating the stability constants of taurine complexes with metal ions [5]. This fact can be used to explain the inconsistency among the stability constants of taurine complexes with copper(II) ions determined in our study and those given in [5] (Table 3). The stability constants of taurine complexes with silver(I) and cadmium(II) ions are comparable with these values described in $[4,8]$ (Table 3).

According to the stability of taurine complexes with the metal : taurine ratio $=1: 2$, transition-metal ions can be arranged in the following order (Table 3): $\mathrm{Mn}(\mathrm{II})<\mathrm{Co}$ (II) $<\mathrm{Ni}$ (II) $<\mathrm{Cu}(\mathrm{II})>\mathrm{Zn}$ (II), which is in agreement with the Irving-Williams series [2].
It should be noted that there is a general correlation between the stability constants of the complexes of taurine and ammonia with transition-metal ions (Table 3 ). It is difficult to draw a conclusion about the structure of the resulting complexes based on these data. Nevertheless, one can assume either the coordination interaction between metal ions and the amino group, or the formation of a six-membered chelate cycle comprising the metal ion and the amino and sulfo groups as a part of taurine. The identification of the structure of the complexes under study requires further research to be carried out.

Thus, with allowance for the values of the stability constants of taurine complexes with metal ions, one can conclude that taurine is a promising precursor for the synthesis of new analytical reagents and sorbents.

\section{ACKNOWLEDGMENTS}

This work was supported by the Competition among PhD students, young scientists, and candidates of sciences for conducting research in the Ural Federal University.

\section{REFERENCES}

1. N. Yu. Rubanyak and E. Yu. Bulychev, Vestn. MITKhT im. M. V. Lomonosova 5 (3), 79 (2010).

2. F. Umland, A. Janssen, D. Thierig, et al., Theorie und practische Anwendung von Komplexbildern (Akademische Verlagsgesellschaft, Frankfurt am Main, 1971; Khimiya, Moscow, 1975).

3. P. Singh and S. Singh, Ultra Sci. Phys. Sci. 20, 243 (2008).

4. S. P. Datta and A. K. Grzybowski, J. Chem. Soc., 1091 (1959).

5. A. Albert, Biochem. J. 47, 531 (1950).

6. C. S. Irving, B. E. Hammer, S. S. Danyluk, et al., J. Inorg. Biochem. 13 (2), 137 (1980).

7. J. Maslowska and L. Chruscinski, Polyhedron 3, 1329 (1984).

8. E. Bottari and M. R. Festa, Talanta 46 (1), 91 (1998).

9. E. C. O'. Brien, E. Farkas, and A. Rockenbauer, J. Inorg. Biochem. 77 (3), 135 (1999).

10. A. Albert and E. P. Sergeant, Ionization Constants of Acids and Bases (Wiley, London, 1962).

11. N. A. Kostromina, V. N. Kumok, and N. A. Skorik, Chemistry of Coordination Compounds (Vysshaya Shkola, Moscow, 1990).

12. J. Inczedy, Analytical Applications of Complex Equilibria (Akademiai Kiado, Budapest, 1976).

13. M. Beck and I. Nagypal, Chemistry of Complex Equilibria (Akademiai Kiado, Budapest, 1986; Mir, Moscow, 1989).

14. Yu. Yu. Lur'e, The Handbook of Analytical Chemistry (Khimiya, Moscow, 1979).

Translated by D. Terpilovskaya 